\title{
Downregulation of MicroRNA-145 Caused by Hepatitis B Virus X Protein Promotes Expression of CUL5 and Contributes to Pathogenesis of Hepatitis B Virus- Associated Hepatocellular Carcinoma
}

\author{
Feng Gao ${ }^{a}$ Xiaoyu Sun ${ }^{b}$ Likun Wang ${ }^{a}$ Shunxiong Tang ${ }^{c}$ Changqing Yan ${ }^{d}$ \\ aLinyi People's Hospital Affiliated to Shandong University, Department of Infectious Disease, Linyi, 'birst \\ Affiliated Hospital of Dalian Medical University, Department of Gastroenterology, Dalian, 'Affiliated \\ Zhongshan Hospital of Dalian University, Department of Invasive Technology, Dalian, 'The Second \\ Hospital of Hebei Medical University, Department of Hepatobiliary Surgery, Shijiazhuang, P. R. China
}

\section{Key Words}

MiR-145 • CUL5 $・ H B X \cdot H C C \cdot$ Cell cycle $・$ Apoptosis

\begin{abstract}
Background: Hepatitis B viral infection-induced hepatocellular carcinoma (HCC) is a major threat to human health in China. Hepatitis B virus X protein (HBX), an HBV protein, has been reported to be involved in regulating the cellular activities of the host cells and is responsible for HCC oncogenesis. Methods and Results: In this study, we performed real-time PCR in tumor tissue samples collected from $53 \mathrm{HCC}$ patients (25 HBV-positive cases and $28 \mathrm{HBV}$ negative cases) to screen the candidate miRNAs that have previously been reported to be aberrantly expressed in HBV-associated HCC and found that miR-145 was significantly downregulated. The following computational analysis identified CUL5 and RAB5C as virtual targets of miR-145, whereas only CUL5 was verified as a validated target gene of miR-145 in liver cells via luciferase reporter assay. In line with this result, we found that both the mRNA and protein expression levels of CUL5 were significantly higher in HBV-positive than in HBVnegative HCC. An in vitro experiment demonstrated a significant decrease in the expression of miRNA-145, a substantial increase in the mRNA and protein expression of CUL5, and an enhanced proliferation of HBX over-expressing HepG2 cells compared with the control. In HepG2.2.15, we found significant decreases in both the expression of CUL5 and the cell growth rate of $\mathrm{H}$ cells transfected with $60 \mathrm{nM}$ miR-145 mimics compared with the scramble controls. Conclusion: HBV infection promotes cell growth, at least partially, through the HBX-induced downregulation of miRNA-145 expression, which is responsible for the oncogenesis of HBVassociated HCC.
\end{abstract}

F. Gao and X.-Y. Sun contributed to the study equally.

Changqing Yan

KARGER 125
The Second Hospital of Hebei Medical University, Department of Hepatobiliary Surgery, 215 Heping Road, Shijiazhuang 276003, (P. R. China)

Tel. +86-311-66002120, E-Mail hepatitisB@126.com 


\section{Introduction}

Hepatocellular carcinoma (HCC) is the leading cause of primary malignant liver tumors, is the third most common cause of cancer-associated death worldwide, and represents a major and global threat to human health [1]. Several risk factors, including infection with hepatitis $\mathrm{C}$ virus (HCV), hepatitis B virus (HBV), alcoholism and other liver diseases substantially contribute to the development of HCC [2]. Among these risk factors, HBV is the most common cause of HCC worldwide and is responsible for the increasing incidence of the disease $[1,2]$.

HBV-encoded X protein (HBX), a 17-kD protein encoded by the ' $\mathrm{X}$ ' open reading frame of the hepatitis $B$ oncogenic viral genome, is a key regulator in the development of HBVassociated HCC, as evidenced by its ability to transactivate oncogenes or tumor suppressive genes that are functionally associated with cellular activities such as apoptosis, signaling, and cell growth [3-5]. In vivo and in vitro experiments demonstrated that HBX is indispensable for in vivo infection and that it promotes the replication of the virus via facilitating mitochondrial calcium uptake. HBX also significantly contributes to HCC tumorigenesis due to its critical role in the initiation of neoplastic transformation [6-8]. In line with this, HBX transgenic mice showed a significantly elevated incidence of hepatitis, steatosis, and dysplasia, as well as HCC in the liver [9-11]. HBV DNA was exclusively integrated into the genome of the HBVassociated HCC tumor tissues in individuals who were positive for the HBX transcript but negative for the HBV surface antigen (HBsAg), thereby suggesting the role of $\mathrm{HBV}$ in genome integration and malignancy transformation [12]. Several studies showed that HBX can promote proliferation, motility and invasion in human hepatocytes by up-regulating MEKK2, MIG, MMP-9, IKKa and Capn4 [13-17]. HBX has also been shown to be involved in controlling tumor growth via modifying cell cycle progression by regulating cell cycle regulatory protein in a calcium-dependent manner $[18,19]$. Aberrantly expressed microRNAs (miRNAs) are also increasingly believed to be functionally involved in the control of various biological processes that are involved in cancer development, such as tumorigenesis, metastasis and proliferation, by negatively regulating the expression of oncogenes or tumor suppressive genes [20]. The role of miRNAs in the pathogenesis of HCC has been extensively investigated, and the dysregulation of miRNAs appear to contribute to HCC development [20,21].

miRNAs have recently been reported to mediate HBX-induced cell proliferation and invasion in HCC [22-26]. Peng et al. reported on differentially expressed miRNAs using a microarray analysis of the expression profiles of HepG2 and HepG2.2.15 cells, which represent a well-known HBX-secreting HCC cell line [27]. In this study, we screened the candidate miRNAs that were previously reported to be aberrantly expressed [27] to identify the miRNA (and its target gene(s)) that mediate the effect of HBX in HCC development.

\section{Materials and Methods}

\section{Patient samples}

A total of 53 tumor tissue samples were collected from 53 histologically confirmed HCC patients who underwent surgical resection at the Second Hospital of Hebei Medical University, Department of Hepatobiliary Surgery. Among them, 25 patients were positive and 28 patients were negative for HBV infection. The specimens were immediately stored at $-80^{\circ} \mathrm{C}$ for future use. Clinicopathological data were obtained from patient records and are described in Table 1. The patients who received radiotherapy or chemotherapy prior to surgery were excluded from the study. Informed consent was obtained from each patient, and the study protocol was approved by the Institute Research Ethics Committee at Hebei Medical University. 
Talbe 1. Clinicopathological data of the participants recruited in this study stratified by the presence of HBV infection status (NS, not significant)

\begin{tabular}{lccc}
\hline & $\begin{array}{c}\text { HBV-positive HCC } \\
(\mathrm{n}=25)\end{array}$ & $\begin{array}{c}\text { HBV-negative HCC } \\
(\mathrm{n}=28)\end{array}$ & P value \\
\hline Age & $48.63 \pm 9.23$ & $49.87 \pm 10.42$ & NS \\
Gender & & & NS \\
$\quad$ Male & 18 & 20 & \\
$\quad$ Female & 7 & 8 & NS \\
Cirrhosis & & & \\
$\quad$ Presence & 13 & 18 & NS \\
$\quad$ Absence & 12 & & \\
Tumor size & & 14 & \\
$\quad<3 \mathrm{~cm}$ & 11 & 14 & \\
$\quad \geq 3 \mathrm{~cm}$ & 14 & & \\
Tumor number & & 6 & \\
$\quad 1$ & 19 & 6 & \\
$\quad \geq 1$ & 6 & 6 & \\
Tumor differentiation & & 18 & \\
$\quad$ Well & 4 & & \\
$\quad$ Moderate & 15 & & \\
Poor & 6 & &
\end{tabular}

$10 \%$ fetal bovine serum containing penicillin-streptomycin antibiotics (Invitrogen, Carlsbad, CA, USA) at 37 ${ }^{\circ} \mathrm{C}$. For transfection with plasmid DNA or oligos, miR-145 mimics were purchased from Ambion (Austin, TX, USA), and the full length of the coding sequence of HBX was amplified and inserted into pcDNA 3.0. The cells were seeded in 6-well plates at a density of $1 \times 10^{6}$ cells/well. After 24 hours, the transfection was conducted using Lipofectamine 2000 (Invitrogen, Carlsbad, CA, USA), per the manufacturer's instructions. The cell lysates were harvested and analyzed via western blot and total RNA isolation. All transfection experiments were repeated at least three times.

RNA isolation and real-time PCR

The total RNA of cells (or liver tissues) was isolated using TRIzol reagent (Invitrogen, Carlsbad, CA, USA). Real-time PCR was performed to determine the expression levels of miR-145, CUL5, RAB5C and U6 (an internal control) using TaqMan Gene Expression Assays (Applied Biosystems, Foster City, CA, USA) according to the manufacturer's instructions. The expressions of specific genes or miRNAs were normalized using U6, and the expression levels were expressed via the comparative Ct method using $2^{-\Delta \Delta C t}$.

\section{Luciferase reporter gene assay}

The wild type full length 3'-untranslated regions (3'-UTRs) of human CUL5 and RAB5C were amplified via PCR. Then, the amplified fragment was inserted into psiCHECK-2 vector and the sequence accuracy was confirmed via direct Sanger sequencing. Subsequently, the predicted "seed sequences" of miR-145 in the 3'-UTR of CUL5 and RAB5C were replaced with the complementary sequences (in RAB5C, 50-56 bp in 3'-UTR of RAB5C, "ACUGGAA" were replaced with "UGACCUG"; in CUL5, 574-580 bp in 3'-UTR of CUL5, "AACUGGA" were replaced with "UUGACCU") using the QuikChange Lightning Site-Directed Mutagenesis Kit (Stratagene, La Jolla, CA, USA) according to the manufacturer's protocol. Verification was performed via direct Sanger sequencing.

For the luciferase assay, HepG2 cells were seeded on 24-well plates and transfected with $100 \mathrm{ng}$ of luciferase reporter vectors (both wild type and mutant) and 30/60 nM of miR-145 mimics or scramble controls. At 48 hours after transfection, firefly and Renilla luciferase activities were determined using the Dual-Luciferase Reporter Assay (Promega, Fitchburg, WI, USA).

\section{Cell growth assay}

Cells were seeded into 96-well plates at a density of $3 \times 10^{3}$ cells per well, and cell proliferation was evaluated $48 \mathrm{~h}$ after the transfection using the Cell Counting Kit-8 (CCK-8) (Dojindo, Kumamoto, Japan) following the manufacturer's instruction. The experiments were carried out at least three times in triplicate wells.

Cell cycle and apoptosis analysis

At $48 \mathrm{~h}$ after transfection, HepG2 cells were digested, washed with phosphate-buffered saline (PBS), and fixed in $70 \%$ ethanol. Cell cycle analyses were performed using propidium iodide (PI) staining. A KARGER 
FACSCalibur flow cytometer (BD Biosciences, San Jose, CA, USA) was used to determine the G0/G1, S, and G2/M fractions.

For apoptosis analysis, the cells were harvested and resuspended in PBS $48 \mathrm{~h}$ post-transfection and then fixed in ethanol under room temperature overnight. The cells were washed with PBS and resuspended in staining solution $(50 \mathrm{mg} / \mathrm{ml}$ propidium iodide, $1 \mathrm{mg} / \mathrm{ml} \mathrm{RNase} \mathrm{A} \mathrm{and} 0.1 \%$ Triton X-100 in PBS, all purchased from Invitrogen, Carlsbad, CA, USA). The stained cells were then analyzed for apoptosis via FACSCalibur flow cytometer (BD Biosciences, San Jose, CA, USA).

\section{Western blot}

The cell or tissue samples were collected and lysed in lysis buffer containing $50 \mathrm{mmol} / \mathrm{l}$ Tris- $\mathrm{HCl}(\mathrm{pH}$ 8.5), $150 \mathrm{mmol} / \mathrm{l} \mathrm{NaCl}, 0.2 \mathrm{~g} / \mathrm{l} \mathrm{NaN3}, 0.1 \mathrm{~g} / \mathrm{l} \mathrm{SDS}, 100 \mu \mathrm{g} / \mathrm{ml}$ phenylmethylsulfonyl fluoride, $1 \mu \mathrm{g} / \mathrm{ml}$ aprotinin, $10 \mathrm{ml} / \mathrm{l} \mathrm{NP}-40$, and $5 \mathrm{~g} / \mathrm{l}$ sodium deoxycholate (all purchased from Sigma-Aldrich, St. Louis, MO). A total of 30-50 $\mu$ g of protein was loaded onto sodium dodecyl sulfate (SDS)-polyacrylamide gel electrophoresis, and the separated protein was then transferred to polyvinylidene fluoride membranes, following by being blocked in 5\% non-fat milk for $2 \mathrm{~h}$. Subsequently, the membrane was incubated with primary antibodies raised against HBX $(1: 1,000)$, CUL5 $(1: 1,500), \beta$-actin $(1: 10,000)$ and RAB5C $(1: 2,000)$ (obtained from Santa Cruz Biotechnology, Santa Cruz, CA) for $1 \mathrm{~h}$ at $37^{\circ} \mathrm{C}$ and incubated overnight at $4^{\circ} \mathrm{C}$, followed by a 1-h incubation with the appropriate horseradish peroxidase-conjugated monoclonal secondary antibody. The bands were visualized using an enhanced chemiluminescence (ECL) detection system (Thermo Fisher Scientific Inc., Rockford, IL, USA).

\section{Statistical analysis}

The statistical analysis was performed using SPSS version 13.0 (SPSS Inc., Chicago, IL, USA). The data are expressed as the means $(\mathrm{M}) \pm$ standard deviation (SD). The gene expression levels were compared using the independent Student's $t$ test between two groups or via one-way ANOVA if more than two groups were involved.

\section{Results}

In this study, we performed real-time PCR on tumor tissue samples collected from 53 HCC patients (25 HBV-positive cases and $28 \mathrm{HBV}$-negative cases) to screen the candidate miRNAs that have previously been reported to be aberrantly expressed in HBV-associated HCC [27], including miR-152, -143, -192, -19b, -18b, -148a, -345, -145, -122, -210, -18a and $-20 \mathrm{~b}$. This was performed to identify the miRNA and its target gene(s) that mediate

Fig. 1. MiR-145

was significantly downregulated in tumor tissue samples collected from HBV-positive HCC as compared with the HBV-negative HCC.

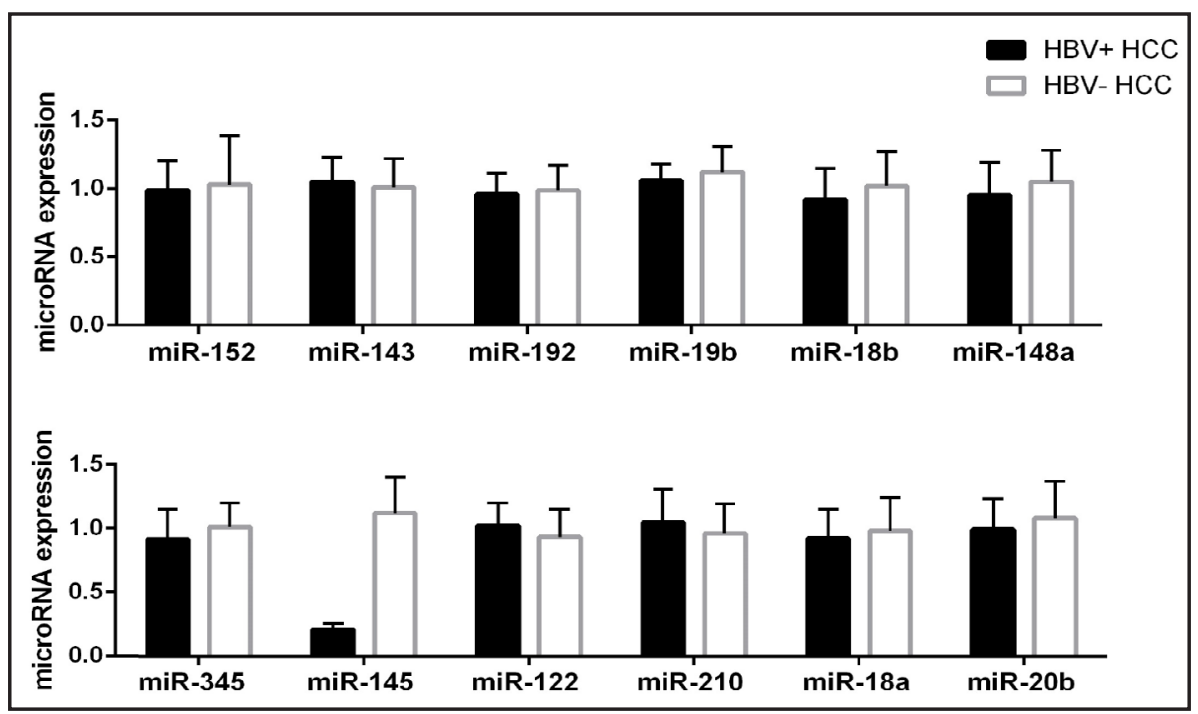


Fig. 2. RAB5C (A) and CUL5 (B) were identified as potential targets of miR-145, and both showed perfect match with mature miR-145 and highly conserved among species.
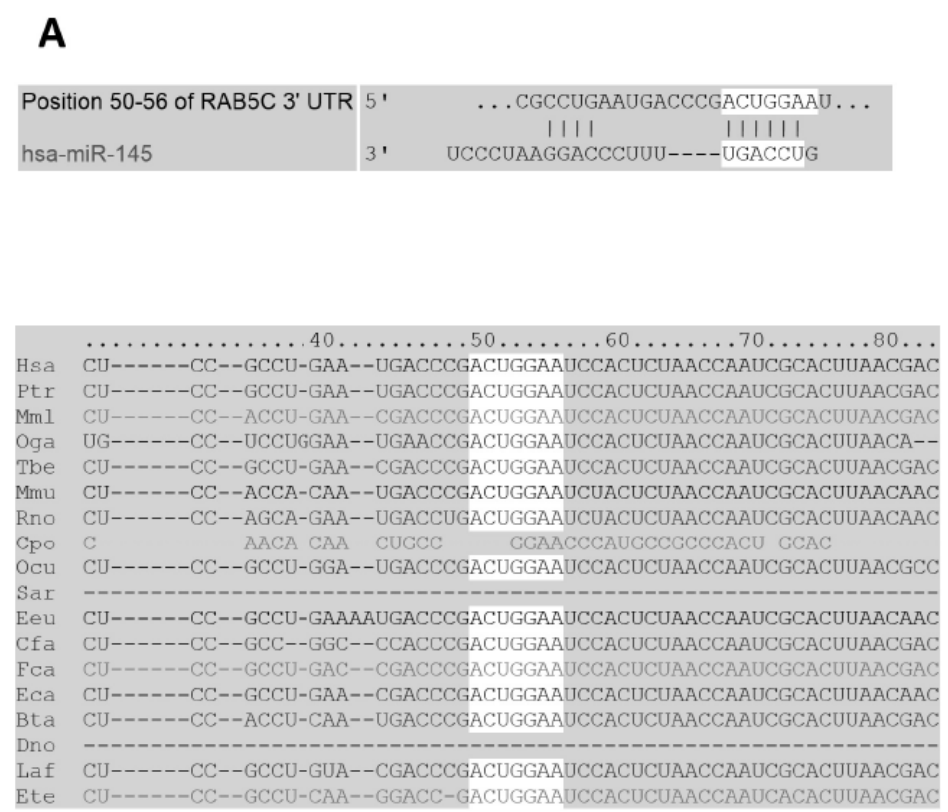

B

\begin{tabular}{|c|c|c|}
\hline $\begin{array}{l}\text { Position } 574-580 \text { of CUL5 3' UTR } \\
\text { hsa-miR-145 }\end{array}$ & & $\begin{array}{c}\text {... AUUGCUCAGUAUAAUAACUGGAU. . . } \\
\qquad \begin{array}{c}11111111 \\
\text { UCCCUAAGGACCCUUUUGACCUG }\end{array}\end{array}$ \\
\hline
\end{tabular}

the effect of HBX in the development of HCC. We identified that miR-145 was significantly downregulated in tumor tissue samples collected from HBV-positive HCC compared with the HBV-negative HCC, as shown in Fig. 1. Due to the reduction in the expression of miR-145 in HBV-related HCC, we hypothesized that the target genes that mediate the effect of miR-145 in the development of HBV-related HCC should be oncogenes and that the downregulation of miR-145 released the physiological inhibition of the oncogenes and promoted tumorigenesis. We subsequently searched the online miRNA database (www.targetscan.org) and identified two potential targets of miR-145, RAB5C and CUL5, both of which showed perfect matches with mature miR-145 and were highly conserved between species (Fig. 2).

To validate the regulatory association between miR-145 and the predicted targets, we subcloned both the wild type and mutant full length 3'-UTR of CUL5 and RAB5C into psiCHECK and a performed luciferase reporter assay in HepG2 cells. We found that the 


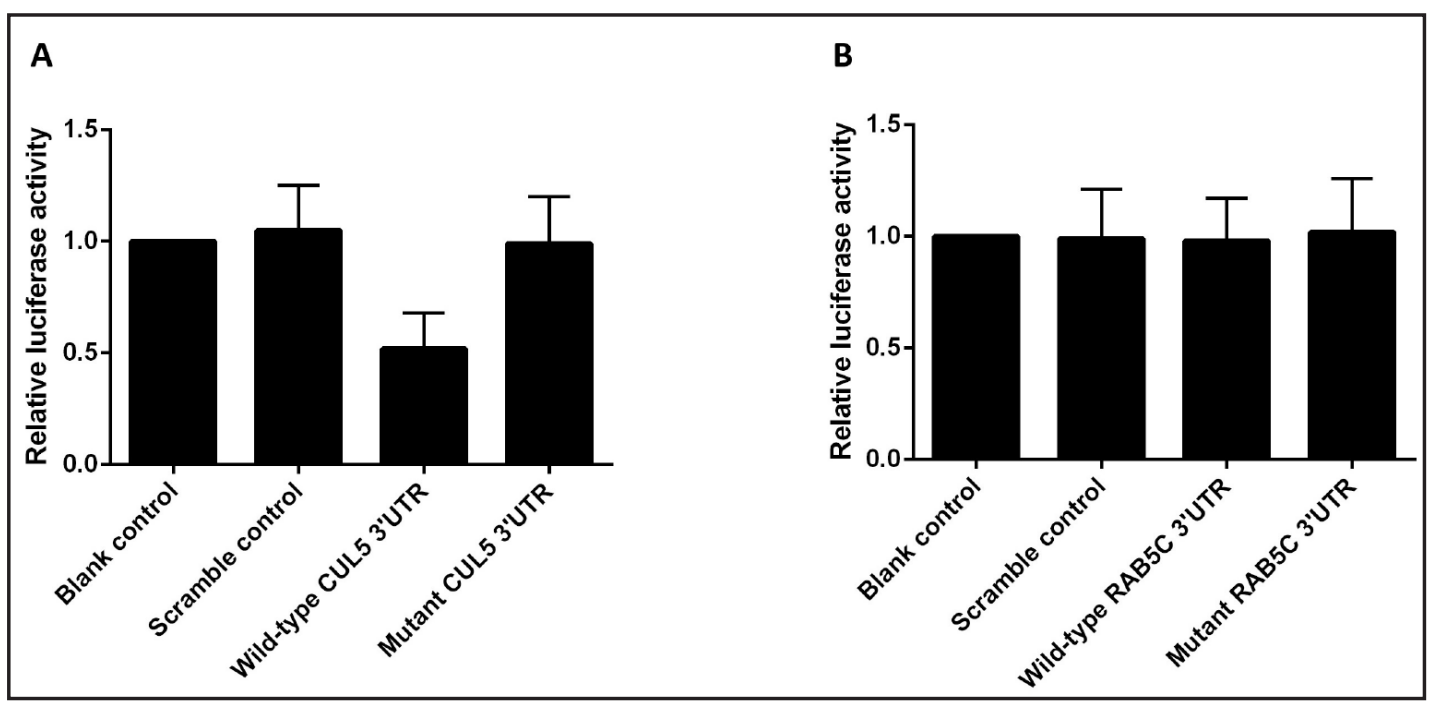

Fig. 3. The cells cotransfected with wild-type CUL5 3'-UTR and miR-145 had a significantly lower luciferase activity than the scramble controls, while those cells transfected with mutant CUL5 3'UTR and miR-145 showed comparable luciferase activity as the controls (A); While both the wild-type and mutant RAB5C 3'-UTR had similar luciferase activity compared with the scramble controls (B).

Fig. 4. Both mRNA (A) and protein (B and $C$ is densitometry analysis of western blot results of B) expression levels of CUL5 were significantly higher in HBV-positive HCC than in HBV-negative HCC.

cells cotransfected with wild-type CUL5 3'UTR and miR-145 had a significantly lower luciferase activity than did the scramble controls, whereas the cells transfected with mutant CUL5 3'UTR and miR-145 showed luciferase activity that was comparable with that of the controls (Fig. 3A). However, both the wild-type and mutant RAB5C 3'-UTR had similar luciferase activity compared with the scramble controls (Fig. 3B). The results of luciferase assay indicated that CUL5 (and not RAB5C) is a target in HepG2 cells.

Furthermore, the expression levels of the two potential targets, CUL5 and RAB5C, were examined in the HCC tissue samples. As shown in Fig. 4, both the mRNA and protein expression levels of CUL5 were significantly higher in HBV-positive HCC than in HBVnegative HCC. The expression levels of RAB5C were comparable between the two groups (data not shown).

To evaluate the effect of HBX on the expression of miR-145 and CUL5, we cloned the coding sequence of HBX into pcDNA3.0
A

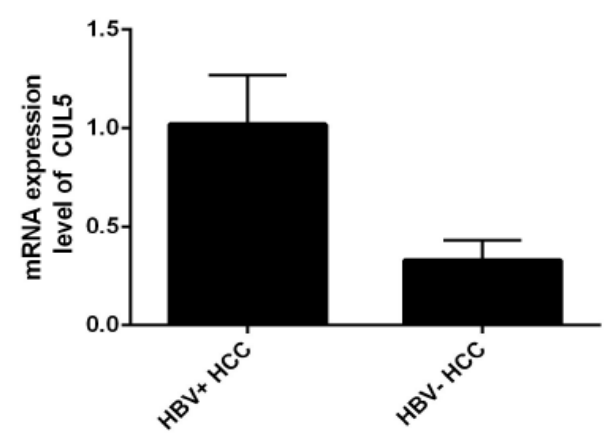

B

CUL5 $\beta$-actin

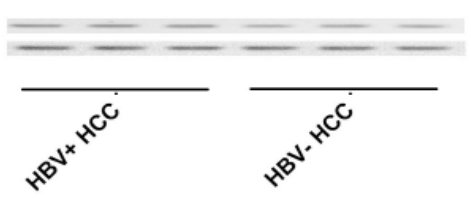

C

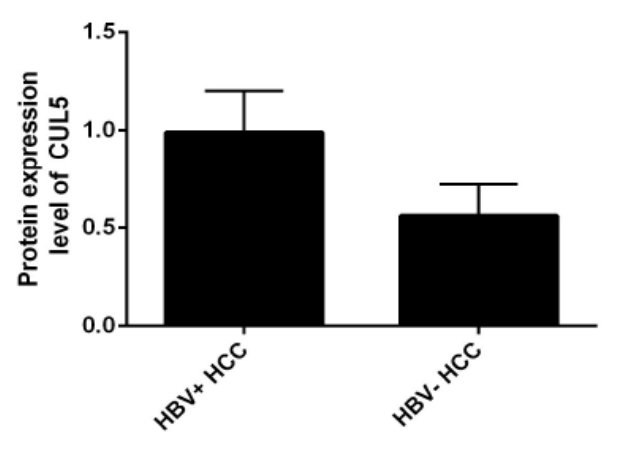




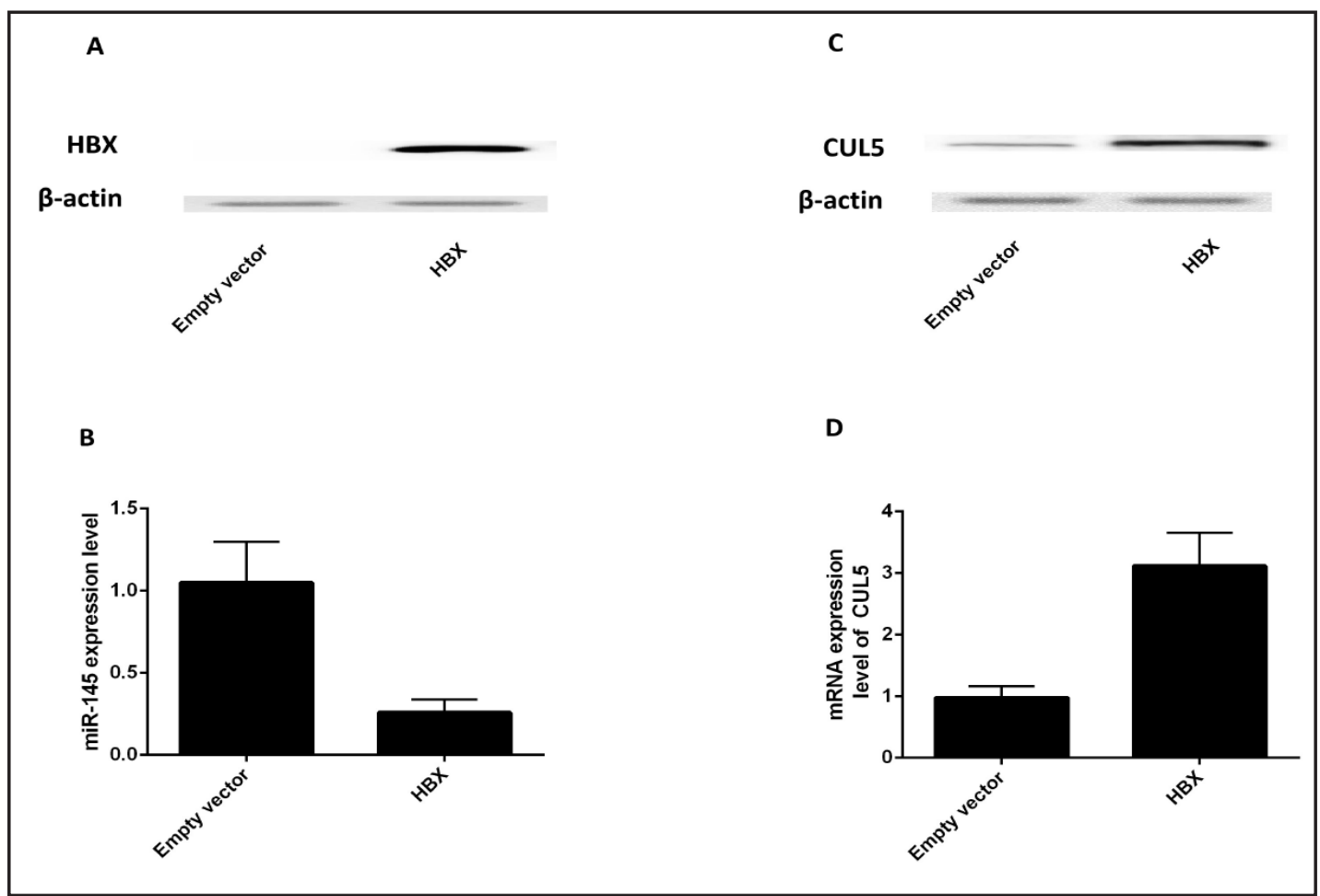

Fig. 5. A. Ectopic expression of HBX in Hep G2 cells; B. The effect of overexpression of HBX on the expression of miR-145; C. The effect of overexpression of HBX on the protein expression of CUL5; D. The effect of overexpression of HBX on the mRNA expression of CUL5.

and transfected it into HepG2 cells. HBX expression was assessed in HBX-transfected cells. The HBX protein was expressed at high levels in HBX-transfected HepG2 cells (Fig. 5A); however, no expression was detected in the empty vector-transfected cells. Next, the effect of HBX over-expression on the intracellular expression of miRNA-145 and CUL5 was studied in HepG2 cells. The cells were transfected with HBX or empty vector, and the cells were collected either for real time PCR or western blot 48 hours after transfection. A significant decrease was observed in the expression of miRNA-145 and a substantial increase in the mRNA and protein expression of CUL5 in HBX over-expressing HepG2 cells compared with empty vector-transfected cells, respectively (Fig. 5B-D). Additionally, the proliferation was analyzed in HBX over-expressing cells using a CCK-8 assay as described in the Materials and Methods section. The proliferation of HepG2 cells transfected with HBX plasmid markedly increased (Fig. 6A) compared with the cells transfected with control plasmid (empty vector). To explore the underlying molecular mechanism, we performed a flow cytometry analysis and found that the overexpression of HBX significantly increased the G2/M fraction, decreased the G0/G1 fraction (Fig. 6B), and significantly suppressed apoptosis (Fig. 6C and D) compared with the cells transfected with empty vector.

We subsequently investigated the effect of the overexpression of miR-145 on the expression of CUL5 and the proliferation and cell cycle status in HepG2.2.15. There was a significant decrease in the expression of CUL5 in the HepG2.2.15 cells transfected with 60 nM miR-145 mimics (Fig. 7). The proliferation of HepG2.2.15 cells transfected with miR-145 mimics significantly decreased (Fig. 8A) compared with the cells that were transfected with the scramble controls. The flow cytometry analysis showed that the overexpression of miR145 significantly decreased the G2/M fraction, increased the G0/G1 fraction (Fig. 8B), and significantly induced apoptosis (Fig. 8C and D) compared with the cells that were transfected with the scramble controls. 
A

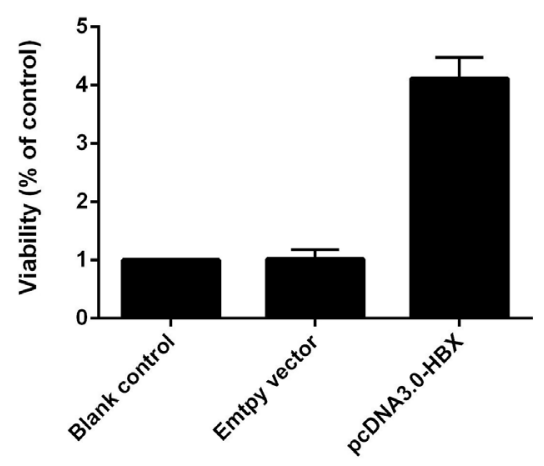

B
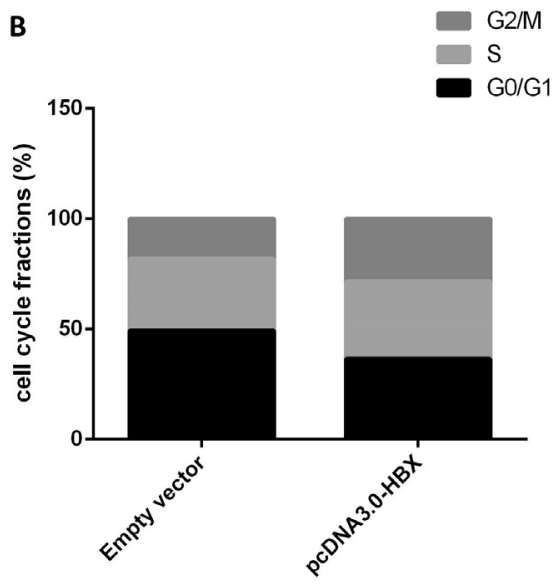

C

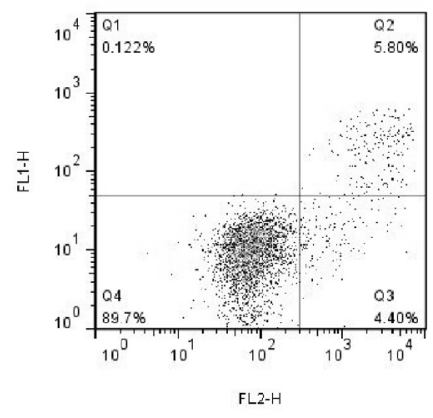

D

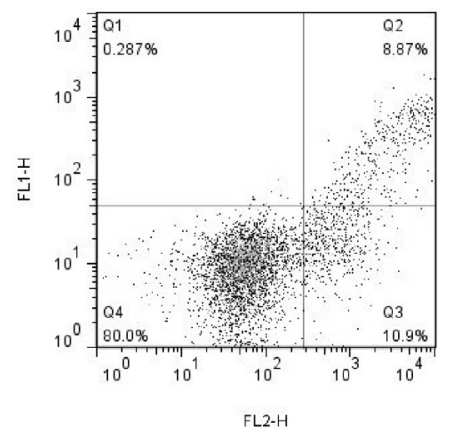

Fig. 6. A. The proliferation of Hep G2 cells transfected with HBX plasmid markedly increased; B. The overexpression of HBX significantly increased fraction of G2/M and decrease G0/G1 fraction as compared with the cells transfected with empty vector; C. The apoptosis status of the Hep G2 cells transfected with empty vector; D. The apoptosis status of the Hep G2 cells transfected with HBX.

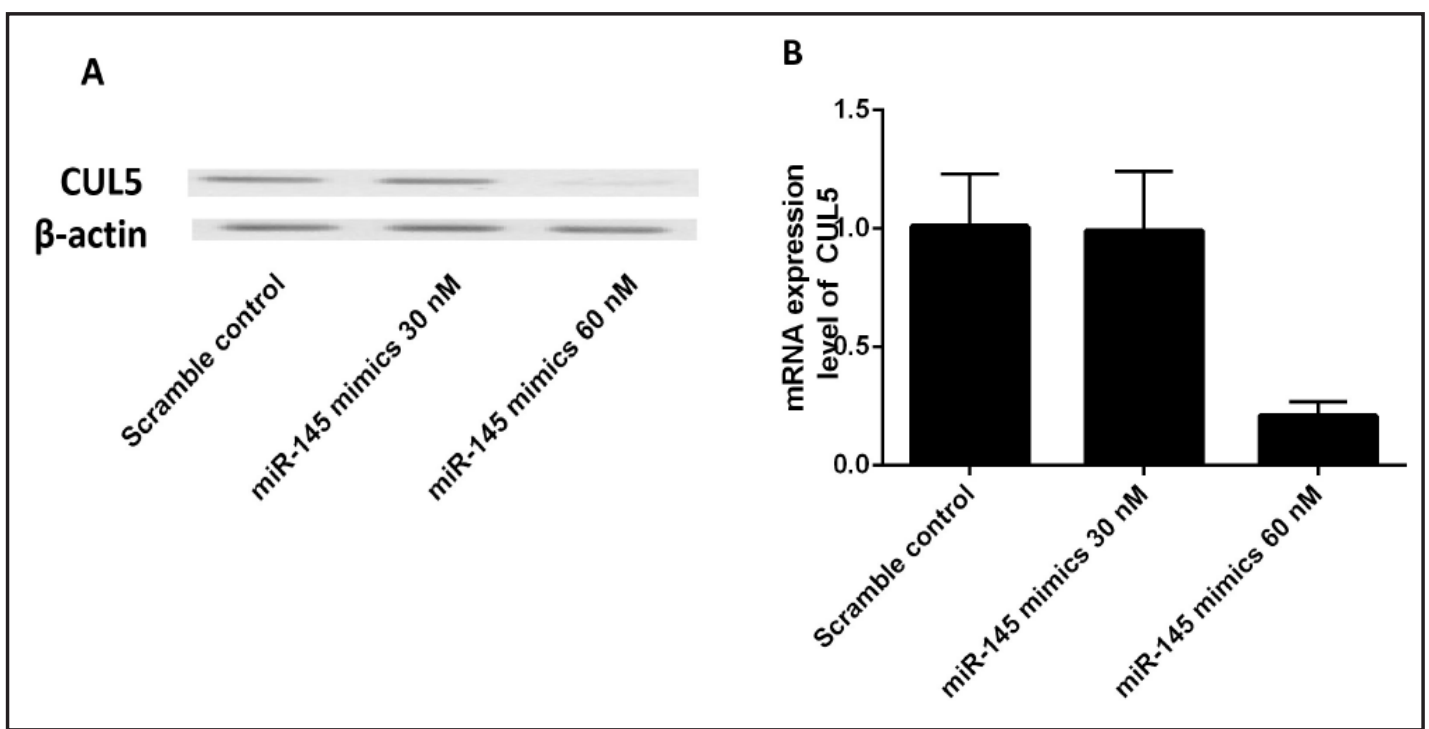

Fig. 7. A significant decrease in the mRNA (A) and protein (B) expression of CUL5 in the Hep G2.1.15 cells transfected with miR-145 mimics $60 \mathrm{nM}$. 
A

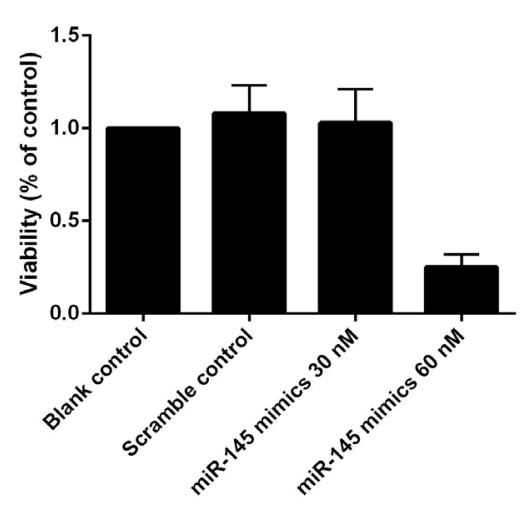

B $\begin{aligned} & \mathrm{G} 2 / \mathrm{M} \\ & \mathrm{S} \\ & \mathrm{G} / \mathrm{G} 1\end{aligned}$

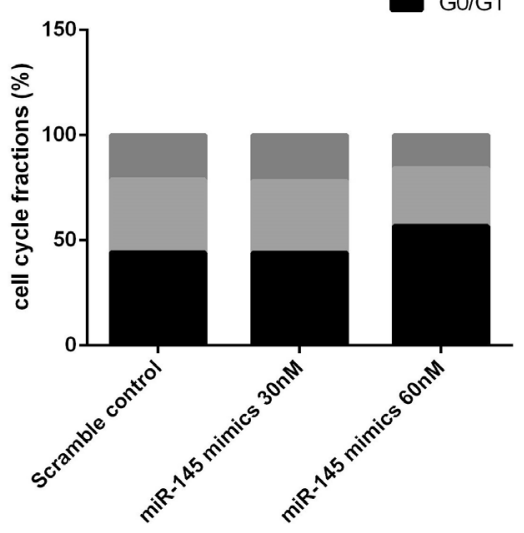

c

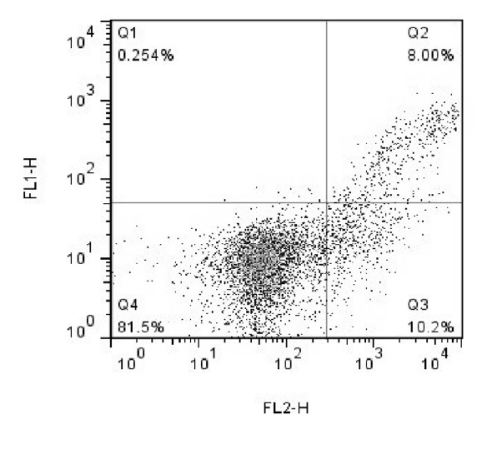

D

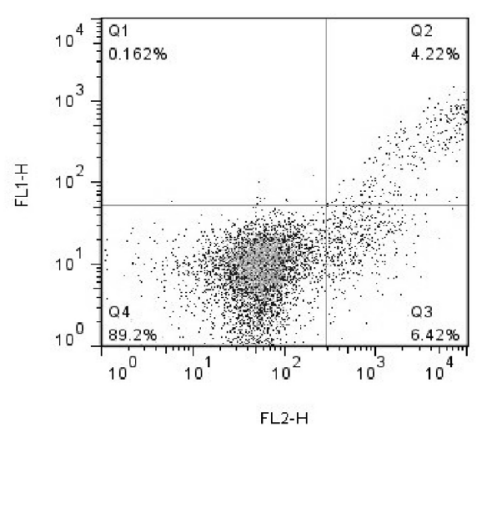

Fig. 8. A. The proliferation of Hep G2.1.15 cells transfected with miR-145 mimics significantly decreased; B. Overexpression of miR-145 significantly decreased fraction of G2/M and increase G0/G1 fraction as compared with the cells transfected with the scramble controls; C. The apoptosis status of the Hep G2.1.15 cells transfected with scramble control; D. The apoptosis status of the Hep G2.1.15 cells transfected with miR-145 mimics $60 \mathrm{nM}$.

\section{Discussion}

It has been estimated that less than $2 \%$ of the human genome involves protein-coding sequences and that more than $90 \%$ of the human genome is transcripted into non-coding RNA (ncRNA), which includes miRNAs. miRNAs are believed to be an essential regulator in a wide range of human biological processes such as proliferation, apoptosis, cell cycle, and metastasis [28]. miRNAs may function as oncogene- or tumor-suppressive genes depending on the target genes. Alterations in miRNA expression have been intensively studied in HCC and have been linked to the molecular mechanism underlying HCC development. The HBX protein is highly conserved among the subtypes of the virus and is universally shared by all mammalian members of Hepadnaviridae [29]. The interactions between HBX and miRNAs have been repeatedly investigated. Zhang et al. reported that HBX overexpression increased the expression of fucosyltransferase by suppressing the expression of miR-15b [30]. The expression of miR-205 was found to be significantly reduced in the liver of HBXtransgenic mice, and the ectopic expression of HBX can abrogate the effect of miR-205 as a tumor suppressive gene [31]. Another study by Cui et al. showed that miR-224 expression was significantly upregulated in HBX-transgenic mice and that the introduction of miR- 
224 promoted tumor formation in HCC via targeting Smad4 [32]. HBX-mediated miRNA expression alternation may function as an essential regulator in hepatocarcinogenesis [33]. miRNAs have recently been reported to mediate HBX-induced cell proliferation and invasion in HCC [22-26]. Peng et al. reported many miRNAs that were differentially expressed between HepG2 and HepG2.2.15 cells based on a microarray analysis of expression profiles [27]. In this study, we performed real-time PCR in tumor tissue samples collected from 53 HCC patients (25 HBV-positive cases and $28 \mathrm{HBV}$-negative cases) to screen candidate miRNAs including miR-152, -143, -192, -19b, -18b, -148a, -345, -145, -122, -210, -18a and -20b. miR-145 was significantly downregulated in the tumor tissue samples collected from HBV-positive HCC compared with HBV-negative HCC (Fig. 1).

MicroRNA-145 (miR-145), a 22-nt miRNA, has been mapped to chromosome 5q in the human genome and functions as a tumor suppressor in variety of cancers such as lung adenocarcinoma, bladder cancer, and colon cancer [34-36]. miR-145 was significantly downregulated in various cancer types [37] and showed an inhibitory effect on the proliferation of human cancer cells [38]. In HCC, the expression of miR-145 was significantly downregulated and was associated with poor histological grade and prognosis in HCC [39]. In this study, we searched the online miRNA database (www.targetscan.org) and identified two potential targets of miR-145, RAB5C and CUL5, both of which showed a perfect match with mature miR-145 and were highly conserved between species (Fig. 2). The following luciferase assay validated CUL5, rather than RAB5C, to be a target of miR-145 in HepG2 cells, as shown in Fig. 3. Additionally, both the mRNA and protein expression levels of CUL5 were significantly higher in HBV-positive HCC than in HBV-negative HCC; the expression levels of RAB5C were comparable between the two groups (data not shown).

As a member of the Cullin-RING E3 ubiquitin family, Cullin-5 (CUL5) has been reported to be functionally involved in numerous cellular activities including the cell cycle and apoptosis [40, 41]. CUL5 is connected to SOCS-box proteins and an E2 ubiquitin-conjugating enzyme by binding to adaptor proteins such as elongins [42]. The complex of CUL5, elongin $\mathrm{A}$ and the elongin $\mathrm{BC}$ complex can efficiently polyubiquitinate the poly II subunit, Rpb1, to influence the cell cycle $[43,44]$. In addition to its role in controlling the cell cycle, CUL5 was also reported to be involved in regulating apoptosis by modulating the phosphorylation of mitogen-activated protein kinase (MAPK) and induce p53 mRNA and protein expression [45]. The activation of tumor suppressor gene $\mathrm{p} 53$, which is caused by the reduction of CUL5, is closely related to the cell apoptosis status [46], indicating that CUL5 may be associated with the apoptosis of human cells. In this study, we transfected HepG2 cells with pcDNA 3.0 with or without HBX and found a significant decrease in the expression of miRNA-145 and a substantial increase in the mRNA and protein expression of CUL5 in HBX over-expressing HepG2 cells compared with empty vector-transfected cells. The proliferation of HepG2 cells transfected with HBX plasmid markedly increased compared with cells transfected with empty vector. Additionally, the flow cytometry analysis showed that the overexpression of HBX significantly increased the G2/M fraction, decreased the G0/G1 fraction, and significantly suppressed apoptosis compared with the cells transfected with empty vector. We also found a significant decrease in the expression of CUL5 in the HepG2.2.15 cells transfected with 60 nM miR-145 mimics. The proliferation of HepG2.2.15 cells transfected with miR-145 mimics significantly decreased compared with cells transfected with the scramble controls, and the flow cytometry analysis showed that the overexpression of miR-145 significantly decreased the G2/M fraction, increased the G0/G1 fraction, and significantly induced apoptosis compared with the cells that were transfected with the scramble controls.

In summary, our data show that HBX at least in part induces cell proliferation via suppressing miRNA-145, which in turn releasing the inhibition of CUL5. Identifying miRNAs that are key initiators of cancer development represents an important step in understanding the molecular mechanism of tumorigenesis, as well as the development of new therapeutic or preventive targets. 


\section{Cellular Physiology Cell Physiol Biochem 2015;37:1547-1559 \begin{tabular}{l|l} 
and Biochemistry Published online: October 30, 2015 & $\begin{array}{l}\text { C 2015 S. Karger AG, Basel } \\
\text { www.karger.com/cpb }\end{array}$ \\
\hline
\end{tabular} \\ Gao et al.: Downregulation of MiR-145 Contributes to Oncogenesis of HCC}

\section{Disclosure Statement}

There is no conflict of interest.

\section{References}

1 El-Serag HB, Rudolph KL: Hepatocellular carcinoma: epidemiology and molecular carcinogenesis. Gastroenterology 2007;132:2557-2576.

2 El-Serag HB: Hepatocellular carcinoma. N Engl J Med 2011;365:1118-112.

3 Peng Z, Zhang Y, Gu W, Wang Z, Li D, Zhang F, Qiu G, Xie K: Integration of the hepatitis B virus X fragment in hepatocellular carcinoma and its effects on the expression of multiple molecules: a key to the cell cycle and apoptosis. Int J Oncol 2005;26:467-473.

4 Yun C, Cho H, Kim SJ, Lee JH, Park SY, Chan GK, Cho H: Mitotic aberration coupled with centrosome amplification is induced by hepatitis B virus X oncoprotein via the Ras-mitogen-activated protein/ extracellular signal-regulated kinase-mitogen-activated protein pathway. Mol Cancer Res 2004;2:159-169. Wu JY, Zhou ZY, Judd A, Cartwright CA, Robinson WS: The hepatitis B virus-encoded transcriptional transactivator hbx appears to be a novel protein serine/threonine kinase. Cell 1990;63:687-695.

6 Liang TJ: Hepatitis B: the virus and disease. Hepatology 2009;49:S13-21.

7 Cha MY, Ryu DK, Jung HS, Chang HE, Ryu WS: Stimulation of hepatitis B virus genome replication by HBx is linked to both nuclear and cytoplasmic HBx expression. J Gen Virol 2009;90:978-986.

$8 \quad$ Yang B and Bouchard MJ: The hepatitis B virus X protein elevates cytosolic calcium signals by modulating mitochondrial calcium uptake. J Virol 2012;86:313-327.

9 Wang C, Yang W, Yan HX, Luo T, Zhang J, Tang L, Wu FQ Zhang HL, Yu LX, Zheng LY, Li YQ Dong W, He YQ, Liu Q, Zou SS, Lin Y, Hu L, Li Z, Wu MC, Wang HY: Hepatitis B virus X (HBx) induces tumorigenicity of hepatic progenitor cells in 3,5-diethoxycarbonyl-1,4-dihydrocollidine-treated HBx transgenic mice. Hepatology 2012;55:108-120.

10 Arzumanyan A, Sambandam V, Clayton MM, , Choi SS, Xie G, Diehl AM, Yu DY, Feitelson MA: Hedgehog signaling blockade delays hepatocarcinogenesis induced by hepatitis B virus X protein. Cancer Res 2012;72:5912-5920.

11 Wang Y, Cui F, Lv Y, Li C, Xu X, Deng C, Wang D, Sun Y, Hu G, Lang Z, Huang C, Yang X: HBsAg and HBx knocked into the p21 locus causes hepatocellular carcinoma in mice. Hepatology 2004;39:318-324.

12 Paterlini P, Poussin K, Kew M, Franco D, Brechot C: Selective accumulation of the X transcript of hepatitis $B$ virus in patients negative for hepatitis B surface antigen with hepatocellular carcinoma. Hepatology 1995;21:313-321.

13 Kong GY, Zhang JP, Zhang S, Shan CL, Ye LH, Zhang XD: Hepatitis B virus X protein promotes hepatoma cell proliferation via upregulation of MEKK2. Acta Pharmacol Sin 2011;32:1173-1180.

14 Xia LM, Huang WJ, Wu JG, Yang YB, Zhang Q Zhou ZZ, Zhu HF, Lei P, Shen GX, Tian DA: HBx protein induces expression of MIG and increases migration of leukocytes through activation of NF-kappaB. Virology 2009;385:335-342.

15 Chung TW, Lee YC and Kim CH: Hepatitis B viral HBx induces matrix metalloproteinase-9 gene expression through activation of ERK and PI-3K/AKT pathways: involvement of invasive potential. FASEB J 2004;18:1123-1125.

16 Huang WC, Chen WS, Chen YJ, Wang LY, Hsu SC, Chen CC, Hung MC: Hepatitis B virus X protein induces IKKalpha nuclear translocation via Akt-dependent phosphorylation to promote the motility of hepatocarcinoma cells. J Cell Physiol 2012;227:1446-1454.

17 Zhang F, Wang Q, Ye L, Feng Y and Zhang X: Hepatitis B virus X protein upregulates expression of calpain small subunit 1 via nuclear factor-kappaB/p65 in hepatoma cells. J Med Virol 2010;82:920-928.

18 Lara-Pezzi E, Majano PL, Yanez-Mo M, Gómez-Gonzalo M, Carretero M, Moreno-Otero R, Sánchez-Madrid F, López-Cabrera M: Effect of the hepatitis B virus HBx protein on integrin-mediated adhesion to and migration on extracellular matrix. J Hepatol 2001;34:409-415.

19 Gearhart TL, Bouchard MJ: The hepatitis B virus HBx protein modulates cell cycle regulatory proteins in cultured primary human hepatocytes. Virus Res 2011;155:363-367. 
20 Kojima K, Takata A, Vadnais C, Otsuka M, Yoshikawa T, Akanuma M, Kondo Y, Kang YJ, Kishikawa T, Kato N, Xie Z, Zhang WJ, Yoshida H, Omata M, Nepveu A, Koike K: MicroRNA122 is a key regulator of alphafetoprotein expression and influences the aggressiveness of hepatocellular carcinoma. Nat Commun 2011;2:338.

21 Kota J, Chivukula RR, O'Donnell KA, Wentzel EA, Montgomery CL, Hwang HW, Chang TC, Vivekanandan P, Torbenson M,Clark KR, Mendell JR, Mendell JT: Therapeutic microRNA delivery suppresses tumorigenesis in a murine liver cancer model. Cell 2009;137:1005-1017.

22 Xu X, Fan Z, Kang L, Han J, Jiang C, Zheng X, Zhu Z, Jiao H, Lin J, Jiang K, Ding L, Zhang H, Cheng L, Fu H, Song Y, Jiang Y, Liu J, Wang R, Du N, Ye Q: Hepatitis B virus X protein represses miRNA-148a to enhance tumorigenesis. J Clin Invest 2013;123:630-645.

23 Wei X, Xiang T, Ren G, Tan C, Liu R, Xu X, Wu Z: miR-101 is down-regulated by the hepatitis B virus x protein and induces aberrant DNA methylation by targeting DNA methyltransferase 3A. Cell Signal 2013;25:439446.

24 Yuan K, Lian Z, Sun B, Clayton MM, Ng IO, Feitelson MA: Role of miR-148a in hepatitis B associated hepatocellular carcinoma. PLoS One 2012;7:e35331.

25 Wu G, Yu F, Xiao Z, Xu K, Xu J, Tang W, Wang J, Song E: Hepatitis B virus X protein downregulates expression of the miR-16 family in malignant hepatocytes in vitro. Br J Cancer 2011;105:146-153.

26 Kong G, Zhang J, Zhang S, Shan C, Ye L, Zhang X: Upregulated microRNA-29a by hepatitis B virus X protein enhances hepatoma cell migration by targeting PTEN in cell culture model. PLoS One 2011;6:e19518.

27 Peng F, Xiao X, Jiang Y, Luo K, Tian Y, Peng M, Zhang M, Xu Y, Gong G: HBx down-regulated Gld2 plays a critical role in HBV-related dysregulation of miR-122. PLoS One 2014;9:e92998.

28 Qiu X, Dong S, Qiao F, Lu S, Song Y, Lao Y, Li Y, Zeng T, Hu J, Zhang L, Zhang L, Fan H: HBx-mediated miR21 upregulation represses tumor-suppressor function of PDCD4 in hepatocellular carcinoma. Oncogene 2013;32:3296-3305.

29 Kodama K, Ogasawara N, Yoshikawa H, Murakami S: Nucleotide sequence of a cloned woodchuck hepatitis virus genome: evolutional relationship between hepadnaviruses. J Virol 1985;56:978-986.

30 Zhang X, Zhang H, Ye L: Effects of hepatitis B virus X protein on the development of liver cancer. J Lab Clin Med 2006;147:58-66.

31 Wu CS, Yen CJ, Chou RH, Chen JN, Huang WC, Wu CY, Yu YL: Downregulation of microRNA-15b by hepatitis $\mathrm{B}$ virus $\mathrm{X}$ enhances hepatocellular carcinoma proliferation via fucosyltransferase 2-induced Globo $\mathrm{H}$ expression. Int J Cancer 2014;134:1638-1647.

32 Cui M, Wang Y, Sun B, Xiao Z, Ye L, Zhang X: MiR-205 modulates abnormal lipid metabolism of hepatoma cells via targeting acyl-CoA synthetase long-chain family member 1 (ACSL1) mRNA. Biochem Biophys Res Commun 2014;444:270-275.

33 Li H, Li Y, Liu D, Sun H, Liu J. miR-224 is critical for celastrol-induced inhibition of migration and invasion of hepatocellular carcinoma cells. Cell Physiol Biochem 2013;32:448-458.

34 Feng L, Allen NS, Simo S, Cooper JA: Cullin 5 regulates Dab1 protein levels and neuron positioning during cortical development. Genes Dev 2007;21:2717-2730.

35 Ayyub C, Sen A, Gonsalves F, Badrinath K, Bhandari P, Shashidhara LS, Krishna S, Rodrigues V: Cullin-5 plays multiple roles in cell fate specification and synapse formation during Drosophila development. Dev Dyn 2005;232:865-875.

36 Yao XL, Liu J, Lee E, Ling GS, McCabe JT: Cullin 5 gene expression in the rat cerebral cortex and hippocampus following traumatic brain injury (TBI). Neurosci Lett 2006;409:65-69.

37 Hu X, Zhang F, Liu XR, Wu YT, Ni YM. Efficacy and potential microRNA mechanism for computed tomography-guided percutaneous radiofrequency ablation of primary lung cancer and lung metastasis from liver cancer. Cell Physiol Biochem 2014;33:1261-1271.

38 Van Dort C, Zhao P, Parmelee K, Capps B, Poel A, Listenberger L, Kossoris J, Wasilevich B, Murrey D, Clare P, Burnatowska-Hledin M: VACM-1, a cul-5 gene, inhibits cellular growth by a mechanism that involves MAPK and p53 signaling pathways. Am J Physiol Cell Physiol 2003;285:C1386-1396.

39 Li Y, Schlamp CL, Poulsen GL, Jackson MW, Griep AE, Nickells RW: p53 regulates apoptotic retinal ganglion cell death induced by N-methyl-D-aspartate. Mol Vis 2002;8:341-350.

40 Kipreos ET, Lander LE, Wing JP, He WW, Hedgecock EM: cul-1 is required for cell cycle exit in elegans and identifies a novel gene family. Cell 1996;85:829-839. 


\section{Cellular Physiology Cell Physiol Biochem 2015;37:1547-1559}

and Biochemistry

41 Lubbers J, Lewis S, Harper E, Hledin MP, Marquez GA, Johnson AE, Graves DR, Burnatowska-Hledin MA: Resveratrol enhances anti-proliferative effect of VACM-1/cul5 in T47D cancer cells. Cell Biol Toxicol 2011;27:95-105.

42 Mahrour N, Redwine WB, Florens L, Swanson SK, Martin-Brown S, Bradford WD, Staehling-Hampton K, Washburn MP,Conaway RC, Conaway JW: Characterization of Cullin-box sequences that direct recruitment of Cul2-Rbx1 and Cul5-Rbx2 modules to Elongin BC-based ubiquitin ligases. J Biol Chem 2008;283:80058013.

43 Yasukawa T, Kamura T, Kitajima S, Conaway RC, Conaway JW, Aso T: Mammalian Elongin A complex mediates DNA-damage-induced ubiquitylation and degradation of Rpb1. EMBO J 2008;27:3256-3266.

44 Zhou J, Lu S, Yang S, Chen H, Shi H, Miao M, Jiao B: MicroRNA-127 post-transcriptionally downregulates Sept7 and suppresses cell growth in hepatocellular carcinoma cells. Cell Physiol Biochem 2014;33:15371546.

45 Dort CV, Zhao P, Parmelee K: VACM-1, a cul-5 gene, inhibits cellular growth by a mechanism that involves MAPK and p53 signaling pathways. Am J Physiol Cell Physiol 2002;285:c1386-c1396.

46 Li Y, Schlamp CL, Poulsen GL: p53 regulates apoptotic retinal ganglion cell death induced by N-methylDaspartate. Mol Vis 2002;8:341-350. 